\title{
TENTATIVAS DE INTEGRAÇÃO NACIONAL BRASILEIRA NA PRIMEIRA METADE DO SÉCULO XX ${ }^{1}$
}

\author{
José Eliomar Filho ${ }^{2}$
}

\section{Resumo}

A estrutura montada por Getúlio Vargas ao chegar ao poder em 1930, de conexão dos espaços frágeis brasileiros através de elementos concretos e a força política alcançada por Assis Chateaubriand com a profusão de órgãos de comunicação espalhados pelo território conectados por uma rede bastante intricada, mas assaz eficiente tornaram esses personagens imprescindíveis no curso para a integração brasileira, que se consolida de fato, pós-1945.

Palavras-Chave: Estado nacional - rede - comunicação - integração nacional

\begin{abstract}
The struture was make for Getúlio Vargas to become president at 1930, of conexion fragile brazilian spaces through concrets elements and politic power obtained for Assis Chateaubriand with the profusion communication stations spreadind for territory was connect to the enough intricate web, but sufficiently efficient, turned those protagonistics in the curse for the brazilian integration, that consolidate at fact, after-1945.
\end{abstract}

Keywords: National state - net - communication - national integration

\section{Introdução}

A grande extensão territorial do Brasil contribui para posicioná-lo como principal nação da parte sul do continente americano, conectada através de seus limites fronteiriços a quase todos os países das Américas Platina, Andina, bem assim das Guianas ${ }^{3}$. Tem ainda fundamental importância na pujança econômica e no dinamismo da política que o Brasil vem

\footnotetext{
${ }^{1}$ Trabalho de conclusão da disciplina Evolução e Organização do Espaço Regional do Mestrado em Geografia (MGEO) da Universidade Federal da Bahia (UFBA).

${ }^{2}$ Mestrando especial da Universidade Federal da Bahia (UFBA). E-mail: jeliomarfilho@ yahoo.com.br

${ }^{3}$ O Brasil só não se limita na América do Sul com o Chile e o Equador.
} 
desenvolvendo ao longo de sua história, contudo já influenciou na produção de desigualdade e desarmonia entre as diversas áreas que constituem o seu território.

Não bastassem as distâncias, a precariedade dos meios de transporte e de comunicação, os aspectos naturais que dificultavam adentrar outros pontos do país e a centralização do poder, incapaz de interligá-lo, também colaboraram para a constituição do espaço territorial brasileiro semelhante a uma série de ilhas com parcas relações até meados do século XX.

Gilberto Freyre (1943) afirmou ser o Brasil, referindo-se à integração do território, muito mais um arquipélago do que um país-continente (ANDRADE \& ANDRADE, 2003, p. 46). Golbery do Couto e Silva (1952) corrobora essa assertiva afirmando que o país, do ponto de vista da circulação, é um conjunto de ilhas, inclusive regionalizando essa problemática de forma a enumerar cinco áreas no país que trabalhavam isoladas, existindo pouca interação entre elas: Ilha Amazônica, península Nordeste, península Centro-Oeste, península Sul e núcleo Central (COUTO E SILVA, 2003, pp. 35-6).

Milton Santos também afirmou que em um primeiro momento, o Brasil era um "arquipélago" com áreas de produção mecanizada e, ao longo do tempo, foram timidamente se interligando até chegarmos, de fato, à integração nacional pós-1945. SANTOS demonstrou que o nosso território passou por três estágios ${ }^{4}$ de utilização por parte do homem. A presente discussão se posiciona na fase da "emergência do espaço mecanizado" (SANTOS \& SILVEIRA, 2001, p. 31), na qual começam a ampliar as ações e a força humana sobre o espaço natural, contrária ao meio anterior em que o tempo e as possibilidades no território eram regidas pela natureza.

As primeiras iniciativas para alterar o quadro da falta de unidade dos espaços brasileiros só começaram a partir da segunda metade do século XIX, com o advento das ferrovias no país que serviram apenas às atividades e populações que ocupavam ou estavam próximas ao litoral, o que era pouco para uma real integração nacional.

O desejo de unidade tão almejado por muitos brasileiros a partir da Independência do Brasil em 1822 adquirira força em 1889 com a Proclamação da República. No início do século XX foram importantes colaboradores da construção dessa integração: Francisco de Assis Chateaubriand Bandeira de Melo e Getúlio Dornelles Vargas. Cada um com seus instrumentos de dominação, seus próprios interesses e com suas formas de lidar e conduzir o

\footnotetext{
${ }^{4}$ Meio natural, meio técnico e meio técnico-científico-informacional (SANTOS \& SILVEIRA, 2001).
} 
poder, se posicionaram na "linha de frente" da luta em favor da interligação dos espaços brasileiros, algo tão necessário para um país com destacadas proporções.

A interação entre os variados espaços do território brasileiro de interesse e necessidade de conexão começa a ser feita a partir de redes formadas de elementos concretos (as ferrovias já citadas acima, rodovias, construção de portos, aeroportos) e abstratos (informação) que representam as redes de circulação e as de comunicação, respectivamente.

Os meios de transporte são tipos de circulação que refletem o poder oficial, sendo um “sinal de potência" (STOURDZÉ apud RAFFESTIN, 1993, p. 202) perante a quem se deseja alcançar, ou seja, a imagem do poder que querendo ou não, é visualizado devido à estrutura que ela abarca e que atende à grande parcela da população. Já as redes de comunicação usam a estratégia da dissimulação para aprofundar seu poder sem ser perceptível, um tipo de poder que vê amplamente sem ser observado.

Através da política Getúlio Vargas fomentou a infra-estrutura. A informação que no período em epígrafe modernizava seus instrumentos e ações, ficou a cargo de Chateau ${ }^{5}$. Como enfatiza UEDA (2005, p. 172), “as redes por si só não protagonizaram a estruturação do espaço: elas estão [...] para atender aos interesses de grupos dominantes, que criam estratégias bem definidas para implantá-las e difundi-las".

A chegada de Vargas em 1930 à Presidência da República, com ajuda direta dos veículos de comunicação de Chateaubriand, teve como conseqüência o empenho do Governo Federal na busca pela agregação dos "arquipélagos nacionais". Nesse período de 15 anos (1930-1945), referente à primeira passagem do gaúcho pelo Palácio do Catete ${ }^{6}$, esses dois personagens da história brasileira marcaram a política do país e, indiretamente, contribuíram para consolidar os contornos do território nacional.

Território, Estado, Nação

O presente artigo propõe historicizar o território, o Estado e a nação brasileira associando ao objetivo de integração do país.

Se o objetivo é tratar da busca do sentido de nação em todos os pontos do território brasileiro, mesmo que longínquos, é de bom grado entender o mecanismo do Estado, "gestor por excelência do território nacional" (SOUZA, 2005, p. 81). Em nosso universo, o Estado é representado por Vargas, dotado de poder para transformar o espaço, recebendo apoio de

\footnotetext{
${ }^{5}$ Devido ao seu nome ser bastante extenso, a imprensa passou a chamá-lo simplesmente de 'Chateau' ou também 'Chatô'.

${ }^{6}$ Então sede do Governo Federal, na cidade do Rio de Janeiro.
} 
“poderes inferiores" (RAFFESTIN, op.cit.), a exemplo da rede de informações dos Diários, trabalhando em parceria.

O território Brasileiro inicialmente área de domínio e apropriação por parte de grupos dominantes europeus, entre o final do século XIX e início do XX já apresentava a sua vasta extensão atual. Expedições, acordos e conquistas na direção oeste e norte do continente sulamericano romperam com o quanto determinado no Tratado de Tordesilhas. Porém, atender a todos os espaços brasileiros de forma igualitária era tarefa muito árdua para os governantes nacionais, em razão dos parcos meios de transporte e comunicação do período.

A localização do centro do poder brasileiro também contribuía para ampliar as disparidades de atuação governamental. A capital do país era o Rio de Janeiro, cidade localizada na parte sudeste do litoral, demasiado distante da Amazônia, por exemplo. A Constituição Republicana de 1891 já determinava a mudança da capital para o Planalto Central, mas "dificuldades de transporte para a área e os interesses contrários à transferência [...] fizeram com que o dispositivo constitucional não se efetivasse por mais de cinqüenta anos" (ANDRADE, 1995, p. 42,).

Esses fatos demonstram que o território era legalmente de domínio governamental, porém, transformar essa apropriação em controle e direcionamento, na prática, era deveras complicado no período antes citado.

O desejo de ampliar o poder governamental frente à extensão territorial brasileira reforçou a atuação e constituição do Estado que, com caráter moderno, teve suas origens no século XV e XVI no Velho Mundo (COSTA, 1992, p. 266), mas que no Brasil vai florescer no início do século XIX.

O Estado surge como um "poder, nascido da sociedade, mas posto acima dela [vai] se distanciando cada vez mais" (ENGELS, 1975 apud Ibidem) da população tornando-se a estrutura de controle e domínio do território. Além de seguir, inicialmente, o interesse da coletividade, o Estado acaba por corresponder também por sua unificação, conforme sintetizou Laski (1973 apud Idem, p. 268), pois, ao atender aos anseios daqueles que representa, o Estado passa a ter um papel ideológico sobre os mesmos, podendo utilizá-los de maneira positiva ou negativa.

De fato, o Estado era o gestor principal e essencial no início do século XX dos espaços brasileiros. Representava os interesses dos cidadãos a partir da Constituição de 1891, passando a ter interesses diversos frente ao território que habitavam. Isso gerava conflitos e, conseqüentemente, necessidade de uma regulação. 
O Brasil no inicio do século passado era uma recém formada República com forte apelo militar ${ }^{7}$. Nossa economia era levada a reboque pelas principais nações da época como Inglaterra e os Estados Unidos. Ambas eram praticantes do laissez-faire, em que o próprio criador deste termo, o Marquês d'Argenson, enfatizava que o Estado "para governar melhor é preciso governar menos" (COSTA, op.cit., p. 280). Quando da quebra da Bolsa de Valores de Nova Iorque em 1929, várias nações que dependiam do seu capital, como o Brasil, sofreram um duro impacto em suas economias, gerando uma grave crise também no aspecto político.

Foi nesse cenário que Vargas assumiu o Estado brasileiro e, seguindo a cartilha keynesiana promoveu transformações profundas no país, acelerando a industrialização, regulando as atividades que envolvem capitais e o gerenciamento da estrutura populacional e territorial.

A Nação, no caso brasileiro, vem a ser o produto dessa formação territorial e constitucional do Estado, sendo a junção histórica de elementos culturais, sociais, políticos e econômicos da população em torno da área que habita. No Brasil, a construção da unidade de nação não partiu da inclusão aleatória das classes sociais na geração de uma consciência nacional para a formação de uma nacionalidade, mas de uma "força interior", ou seja, uma ação política organizada com a intenção de forjar uma atitude, um comportamento, para o povo que direcionou no período 1930-1945, ao pensamento único do interesse do Estado visando ser de interesse coletivo, semelhante ao que ocorreu na Alemanha, conforme assinalou Jacques Droz (apud Idem, p. 301).

Wainberg (2003, p. 54) afirma que "a angústia por identidade levaria [...] Vargas a tornar o Estado um ator mediador decisivo na empreitada da construção do homem brasileiro". Getúlio, inspirado pelo Modernismo de 1922, quando intelectuais brasileiros fizeram o Brasil olhar para si, com a intenção de encontrar as suas mais profundas raízes, forçou a propagação dessa cultura que adquiriu o status de oficial no pais, como ferramenta para a integração nacional.

A Chateau coube a responsabilidade através dos Diários de difundir essa cultura, sendo essa a sua contribuição à nacionalidade brasileira, o que se tornou fundamental para a integração dos espaços aos quais passou a alcançar a partir de 1930. “A obra [...] realizada por Assis Chateaubriand expressou, a sua época, o Brasil que se fazia, que se queria nação e que buscava sua identidade" (Idem, p. 277).

\footnotetext{
${ }^{7}$ Os dois primeiros presidentes republicanos do Brasil foram Marechais.
} 
O caminho traçado

O encontro de Vargas e Chatô aconteceu na então Capital Federal, por volta de 1924 e 1925, quando Getúlio exercia o cargo de deputado federal pelo Rio Grande do Sul.

Chateaubriand, à época, era o recém-mandatário d' $O J$ ornal ${ }^{8}$, sete anos após ter migrado do Recife em busca do seu principal objetivo: adquirir um diário com a intenção de erguer uma rede de jornais, visto que, sua opinião poderia alcançar um número maior de pessoas em todos os rincões do país, lhe proporcionando poder e influência no cenário político nacional. A este cabia desbravar o território, restando aos de "almas mais pacíficas" (CARNEIRO, 1999, p. 115) o povoamento e a ocupação.

Getúlio Vargas, advogado gaúcho com forte influência caudilha herdada de sua família, participava ativamente da política em São Borja, quando foi "apadrinhado" por Borges de Medeiros, o principal responsável pela guinada da sua carreira pública. Primeiro como Deputado Federal seguidas vezes, entre os anos de 1909 e 1922, quando, após um ano, tomou posse na Câmara dos Deputados, na Capital Federal. Ali, Vargas ampliou seus contatos e costurou alianças com importantes figuras da política nacional da época, as quais, posteriormente, o ajudaram a assumir o cargo de Presidente da República.

O desejo de integrar o país fez ocorrer o encontro desses dois brasileiros, e, de acordo com os relatos de Chateaubriand, desde o primeiro contato que tiveram Getúlio externou o seu profundo desejo de concretizar a unidade nacional. Na oportunidade, Assis expôs ao gaúcho o plano de ampliar rapidamente o número de jornais sob sua tutela nas principais praças (São Paulo, Rio de Janeiro e Minas Gerais), a partir de onde os expandiria pelo país, criando uma cadeia nacional de informações (MORAIS, 1994, pp. 144-5).

Em 1928, Getúlio regressa aos pampas como Governador. Contudo, nos três anos que esteve no Rio de Janeiro em contato direto com o jornalista, ele pôde solidificar as bases rumo ao Palácio do Catete. Vargas foi nomeado, em 1926, Ministro da Fazenda do Presidente Washington Luís e, apesar das ofensivas dos jornais de Chatô ${ }^{9}$ contra o Governo Federal, os laços que estreitavam a relação entre ambos ficavam cada vez mais fortes.

\footnotetext{
${ }^{8}$ Assis Chateaubriand adquiriu o matutino $O$ Jornal em 30 de outubro de 1924 das mãos do jornalista Renato Toledo Lopes.

${ }^{9}$ Até 1928, Assis Chateaubriand possuía dois periódicos. O Jornal da Capital Federal e o Diário da Noite de São Paulo.
} 
No final da década de 20 [século XX] aliaram-se dois dos brasileiros mais inteligentes e poderosos do século - Assis Chateaubriand e Gétulio Vargas , que teriam por quase trinta anos uma vida de serviços mútuo e mal velada admiração, 'cozida, porém, a canivetadas', no entender do jornalista. Graças a Vargas e à Aliança Liberal, os Associados ganharam força, expandindo sua influência e anexando vários diários para formar seu império jornalístico. (CARNEIRO, 1999, p. 118)

A Aliança Liberal, que tanto colaborou para a expansão e consolidação da marca Diários Associados ${ }^{10}$, foi um bloco político lançado oficialmente em agosto de 1929. Era formada pelos principais "caciques" de Minas Gerais, Paraíba e Rio Grande do Sul, acompanhada de grupos menores de São Paulo e do Rio de Janeiro. Tinha o objetivo de ser a opção oposicionista nas eleições presidenciais de 1930 e, para alcançar essa meta, precisava de um difusor dos seus ideais e desígnios. Uniu-se a fome com a vontade de comer.

O candidato lançado pela Aliança Liberal era Getúlio Vargas, que possuía estreita ligação com Chateaubriand de quem já havia escutado sobre a intenção de ampliar espacialmente o número de seus jornais. Para que as propostas liberais fossem ventiladas o mais distante possível, era necessário dar vazão aos planos do jornalista paraibano. O grupo político então capitalizou o projeto de Assis e, às portas do pleito, ele já tinha adquirido quatro jornais ${ }^{11}$, além dos dois que já possuía.

Antes da sua sanção, em 1929, o grupo político liberal já concatenava para a candidatura de Getúlio, contudo, foi apenas a partir da associação com a cadeia de diários que se tornaram conhecidas as propostas e a personalidade de Vargas em quatro cidades importantes do país, com exceção do Rio Grande do Sul, onde já tinha carreira consolidada.

Nossos dois personagens esquematizaram o lançamento de uma revista que "seria semanal, com tiragem de 50 mil exemplares [...], circulariam em todas as capitais e principais cidades do Brasil" (MORAIS, op. cit., p. 178). A Cruzeiro chegou às bancas em 10 de dezembro de 1928, simultaneamente, nos centros e em pontos longínquos do território nacional, abarcando todas as regiões. Vargas, em conversa com o principal financiador do semanário afirmou profeticamente que "essa revista vai ser um bacamarte para nossos planos

\footnotetext{
${ }^{10}$ Termo criado no final de 1930 por Assis Chateaubriand em resposta a uma missiva de um leitor a um de seus diários que o questionava sobre o posicionamento oposicionista ao governo Vargas. O jornalista relatou que os jornais dele não haviam se transformado em um partido de oposição. Tinha sim, se acostumado "a falar alto [...] e, como não temos hábitos palacianos, preferimos a tribuna dos nossos diários associados para debater os atos do governo" MORAES, 1994, p. 261. Meses depois, os 'Diários Associados' tornavam-se marca e passaria a ser o nome oficial do conglomerado de meios de comunicação espalhados pelo Brasil sob a tutela de Assis Chateaubriand.

${ }^{11}$ Diário de São Paulo, Estado de Minas, Diário de Notícias em Porto Alegre e outro Diário da Noite, só que na Capital Federal. Todos arrebatados em 1929.
} 
políticos futuros." (Idem, p. 179). Ele tinha razão. Cruzeiro foi o primeiro veículo de comunicação no Brasil a unir os espaços com maior concentração populacional do país em torno da informação.

No dia 10 de dezembro, por fim, consegue-se um verdadeiro milagre para um país cujas comunicações ainda estavam na idade da pedra: a revista Cruzeiro estava nas bancas de Belém e Porto Alegre, simultaneamente. Além de usar caminhões, barcos e trens, Chateaubriand fretou um bimotor [...] para que nenhuma cidade importante fosse esquecida pela distribuição. (MORAIS, op.cit., p. 187)

O passo que o gaucho e o paraibano deram a partir daí foi decisivo para a entrada dos dois no jogo político nacional da época. Mesmo com a relação apinhada de "canivetadas" ambos sabiam o que realmente interessava: poder e coerção (WAINBERG, 2003, p. 51).

Tentativas de integração nacional

[...] com o advento da ferrovia na segunda metade do século XIX que podemos falar no Brasil de uma primeira tentativa de instauração de uma rede técnica com vistas a um controle, captura e gestão eficaz dos fluxos. Antes da ferrovia, não se pode falar em 'rede' no Brasil, seja como objeto técnico material, seja como idéia ou decurso. (FERRAZ, 2004, p. 21)

Como se observa nas palavras de Fernando Ferraz, os primeiros sinais de conexão de espaços no território nacional se devem às linhas férreas. Estas, apesar de 'não constituírem uma rede destinada a unir as diversas regiões interior entre si $^{12}$, mas ligar os centros produtores e os portos, não deixam de consistir em elemento de comunicação e interação entre fonte e destino. As áreas por onde passavam essas linhas férreas estabeleciam uma relação com estes instrumentos técnicos, sofrendo influência deles a partir dos produtos, pessoas e informação que circulavam entre os locais de fabrico e de distribuição. Era mais um 'arquipélago' que se desenvolvia, porém começava a se observar uma ruptura desse isolamento devido a um contato que passava a ser estabelecido com o mundo exterior através dos portos.

Ainda sobre a citação acima em epígrafe, antes de 1854 (ano da instalação da primeira ferrovia) não se pode estabelecer que houveram tentativas plausíveis de integração nacional a partir de redes pois elas passam a existir no Brasil com o domínio técnico sobre a natureza estabelecendo uma orientação mecânica se sobrepondo à ordem natural anterior. As ligações entre espaços nacionais anteriores ao estabelecimento do meio técnico no país, tanto a partir

\footnotetext{
${ }^{12}$ GALEANO, Eduardo. As veias abertas da América Latina. Rio de Janeiro: Paz e Terra, 35ª ed., 1992, p. 216.
} 
de comunicações quanto de transportes, não chegam a desencadear um início da busca pela integração territorial.

São louváveis as formas de ligação existentes antes da metade do século XIX, como a navegação fluvial e também as rotas por terra. O que nos faz não apontar estas como tentativas efetivas de interligação do Brasil é a frágil conexidade que elas apresentavam, justamente pelo impedimento que o meio natural proporcionava e, como buscamos a ligação a partir de redes técnicas quando instrumentos mecanizados se sobrepõem ao espaço ainda pouco alterado, esses exemplos não são contemplados.

$\mathrm{Na}$ navegação fluvial, PRADO JÚNIOR (2008) aponta a dificuldade que se apresentava para fluir pelo território ao afirmar que "os rios brasileiros [...] são com raríssimas exceções muito impróprios à navegação”. A única área de fácil movimentação pelos rios é a Amazônia, mas que nos séculos iniciais do Brasil era mais um exemplo de "ilha" extremamente isolada do restante. Além disso, ele demonstra que os rios nacionais em sua maioria são voltados para o continente o que dificultava a navegação, já que era a força humana que movia as embarcações. As vias por terra enfrentavam o problema das questões naturais (relevo, pluviosidade, mata densa) e de falta de infra-estrutura como pontes para ser possível travessia em áreas em que rios impossibilitavam a passagem, forçando caminhadas extras até se obter um ponto possível de passagem.

As ferrovias ao se instalarem, alteram essa relação com a natureza, pois ela foi capaz de percorrer o território (em que hajam trilhos) sem que o meio natural lhe gere maiores percalços. Isso faz o país alcançar o meio e o período técnico (SANTOS, 1994), em que FERRAZ (2002) denomina que essa movimentação pelo espaço brasileiro de elementos técnicos capazes de passar a interligar pontos que antes a natureza gerava uma dificuldade de circulação são conhecidos como dispositivos de fluidez e fazemos uma associação, também, com as trajetividades, termo proposto por VIRILIO (1996 apud FERRAZ, 2004), que são formas de aproximação existentes entre o homem e os objetos a partir das relações que passam a acontecer através de ligações para fluidez pelo território, para comunicação e para o comércio.

Dessa forma, o país passa do período pré-técnico (ou natural? ${ }^{13}$ ) para o momento técnico. “[...] com incorporação das máquinas ao território (ferrovias, portos, telégrafo), estaríamos autorizados a apontar um meio técnico da circulação mecanizada" (SANTOS \&

\footnotetext{
${ }^{13}$ SANTOS (2001, p.28) afirma existir um 'relativismo de denominações' em que o homem fazendo parte do meio geográfico insere nele um contexto social e que sua ação leva a crer existir técnicas. Mesmo que a natureza, nesse período chamado 'natural', coloque-se como detentora do espaço perante o homem, suas movimentações sob ele inclui algum meio técnico por mais rudimentar que fosse.
} 
SILVEIRA, 2006, p. 27) e o florescimento de uma rede de circulação no país, todavia ainda era pouco tendo como análise o sentido de integração para o Brasil.

O sistema de portos era outro mecanismo capaz de contribuir para a ligação entre os “arquipélagos" brasileiros através do imenso litoral. Também na segunda metade do século XIX, cidades tão distantes, mas estrategicamente bem localizadas, como Rio de Janeiro, Salvador, Recife, São Luís e Belém adquiriram seus primeiros cais e estabeleceram um elo de circulação de produtos, pessoas e informação. A industrialização e a exploração econômica de produtos primários impulsionaram a instalação de muitas estradas de ferro e portos pelo Brasil. Tinham como objetivo tão somente satisfazer a necessidade dos locais de produção e dos de consumo.

Posteriormente, em menor intensidade, as rodovias e aeroportos apareceram no rol das atividades de contribuição conectiva das "ilhas" nacionais. Observa-se que em 1952 havia apenas 302.147 quilômetros de estradas de rodagem, quase seis vezes menos do que em 1995. Em relação à aviação, circulava no Brasil, em 1945, 245.672 passageiros, vinte e seis vezes menos que trinta anos depois (SANTOS \& SILVEIRA, op.cit.).

A informação também foi um elemento que concorreu para a integração brasileira, nos lançando em busca de fontes e conceituação teórica.

Desde as cartas trocadas entre a corte portuguesa e seus enviados à colônia brasileira a fim de obter relatos e impressões sobre o lugar conquistado que a comunicação serve de elo entre esses espaços longínquos e o poder supremo, o qual, dessa forma, pôde impor mudanças ao local dominado.

O poder sobre as informações foi essencial para que o governo colonial controlasse a proliferação de notícias, evitando a influência de outros grupos no interior do território subjugado. Não por acaso, o primeiro jornal brasileiro ${ }^{14}$ foi editado em Londres, proibido de circular no Brasil por defender ideias como a Abolição da Escravatura, transferência da capital para o centro do país e sua independência (CARNEIRO, op.cit., pp. 33-6).

A difusão da informação no início do século XX vai além da propagação de notícias. Passa a atuar na conexão de espaços frágeis, do ponto de vista da integração, em áreas já consolidadas. Esse fluxo, à época, se deu por distintos instrumentos, a exemplo do telégrafo e do telefone. Contudo, focamos o presente trabalho na circulação de informações jornalísticas, agrupadas em uma Rede de comunicações que até 1950 era composta de rádios, jornais e revistas.

\footnotetext{
${ }^{14}$ Correio Braziliense, de 1808
} 
Três medidas adotadas pelos Diários Associados apontaram na direção da integralização do espaço brasileiro, quais sejam: a construção da Agência Meridional de retransmissão de notícias para órgãos da Rede Associada; a aquisição (prática mais realizada) e a formação (em reduzida quantidade) de jornais, revistas, a exemplo d'O Cruzeiro, e rádios distribuídas pelo território nacional; e a campanha de doação de aviões frente aos aeroclubes espalhados pelo Brasil.

Dias (2005) demonstra existir quatro grandes fluxos ${ }^{15}$ utilizados largamente no espaço geográfico. As limitações técnicas evitam que haja comparações entre os fluxos informacionais, contextualizados pela autora, e que se referem ao período atual, e os trabalhados no presente artigo. Os nossos movimentos de informação dizem respeito às conexões via telégrafo, telefone e rádio, que, à época, resultavam numa frágil interligação, tornando pouco ágil a transmissão de notícias, o que despendia tempo considerável para essa profusão, tomando como base os níveis de fluxo atuais.

Ainda que o fluxo informacional de que dispunha os Diários Associados não contasse com a elasticidade das redes de comunicação atuais, este possuía uma característica que potencializava a sua força, qual seja, a capacidade de se adequar, adaptar e moldar-se ao espaço, de acordo com os seus interesses.

\begin{abstract}
A rede aparece como fios seguros de uma rede flexível que pode se moldar conforme as situações concretas e, por isso mesmo, se deformar para melhor reter. A rede é proteiforme, móvel e inacabada, e é dessa falta de acabamento que ela tira sua força no espaço e no tempo: se adapta às variações do espaço e às mudanças que advêm no tempo. A rede faz e desfaz as prisões do espaço, tornado território: tanto libera como aprisiona. É o porquê de ela ser o 'instrumento' por excelência do poder. (RAFFESTIN, 1993, p. 204)
\end{abstract}

A política varguista representava a rede/sistema de circulação proposta por Raffestin, a qual seria o potencializador da presença do Estado perante a população, a partir dos projetos políticos e econômicos que evoluíam com o tempo.

Os Diários demonstraram ser o exemplo da rede de comunicação, mobilizando estratégias e interesses sem a mesma visibilidade que a de circulação, contudo decisiva para o sucesso do poder desta.

A Agência Meridional, um dos símbolos da conexão entre os veículos de informação de Assis Chateaubriand no Brasil da década de 1930, copiou prática bastante utilizada na Europa e nos Estados Unidos, relativa à distribuição de matérias, notícias e fotos pelos órgãos pertencentes a determinada cadeia de comunicação. Os Diários Associados

\footnotetext{
${ }^{15}$ Fluxos migratórios, fluxos de mercadorias, fluxos informacionais e os fluxos monetário e financeiros.
} 
'profissionalizava[m] o que já era feito amadoristicamente entre suas empresas' (MORAIS, op.cit., p. 266). O órgão fundado em 1931, no início da era Vargas, gerava duas importantes conseqüências para os Associados. A primeira foi financeira, pois a empresa produtora da notícia ganhava royalties pelo que foi noticiado em outros jornais, passando, posteriormente, a Meridional, a comercializar essas notícias também com veículos que não faziam parte da rede. A segunda foi de cunho político. As notícias de uma série de jornais, todas oriundas de uma mesma fonte, geraram uma espécie de opinião única perante o leitor. A informação associada adquiria um know-how de qualidade e de credibilidade pelo Brasil.

Chateaubriand também notou rapidamente que para alcançar seus interesses dentro do cenário político nacional, através de meios de comunicação, precisava adquirir ou criar jornais pelo Brasil. Nos quinze anos entre a entrada e a saída de Vargas do governo brasileiro, os Diários inseriram ao conglomerado entre 17 e 24 jornais, cerca de $90 \%$ deles comprados em investidas pelo território brasileiro ${ }^{16}$. Passaram a fazer parte dos Associados 16 rádios, todavia apenas as difusoras Tupi de São Paulo e do Rio de Janeiro foram efetivamente fundadas pelo grupo $^{17}$. Destacava-se, contudo, a revista $O$ Cruzeiro, com distribuição quase que improvável. $\mathrm{O}$ magazine chegava às principais cidades do território brasileiro e ainda eram colocadas ao mesmo tempo à venda nas bancas de revista, isso há cerca de 80 anos.

Os referidos veículos de informação ligados à Agência Meridional e difusora das notícias que ocorriam pelo país afora geraram uma intricada conexão e, de certa forma, eliminaram a visão de "ilhas" que as regiões brasileiras possuíam, pois passaram a integrar-se, comunicando-se e conhecendo/reconhecendo-se através das notícias que veiculavam.

Dentre uma série de campanhas que Chateaubriand lançou e que se espalhou rapidamente pelo Brasil através da Rede Associada, ganhando as ruas e tornando-se um sucesso de popularidade, estava a "Campanha Nacional de Aviação" (CARNEIRO, op.cit.) ou 'Dê Asas à Juventude' (MORAIS, op.cit.). Encaixava-se no plano de integração nacional. Junto com o Estado Novo Chateau criou uma campanha para a doação de monomotores junto aos aeroclubes que, à época, se multiplicavam pelo país. Os aeroplanos eram doados com a intenção de treinamento de pilotos, visando formar pessoal para assistir as empresas aéreas que começavam a circular pelo espaço brasileiro. Com a formação de pessoal para guiar os

\footnotetext{
${ }^{16}$ Há 17 órgãos com confirmação de que foram adquiridos ou inaugurados no período 1930-1945 (MORAIS, 1994) (CARNEIRO, 1999) (DIÁRIOS, 2009). Restam sete: $O$ Globo de São Luís-MA foi incorporado entre 1942 a 1955; Os outros seis (Jornal de Joinville, A nação, Diário de Aracaju, Diário do Norte, Pacotilha e Folha de Goiás), não há informações encontradas sobre o período em que passaram a fazer parte dos Diários Associados. Dos 17 jornais com dados precisos sobre suas entradas nos Associados, 15 foram comprados. Apenas o Diário da Tarde de Belo Horizonte-MG e o Correio do Paraná em Curitiba-PR foram criados pela empresa de Chateaubriand em 1931 e 1937, respectivamente.

1713 emissoras foram compradas. A Rádio Araripe de Crato foi adquirida entre 1942 e 1955.
} 
aparelhos o Brasil esperava construir uma infra-estrutura para aumentar o tráfego aéreo no país, imprescindível pela robustez do seu território. A iniciativa servia para integrar a aviação aos demais meios de transporte utilizados (ferrovia, rodovia, hidrovia), sendo que com os aviões ampliava-se à velocidade de fluxo e diminuía as distâncias entre os espaços.

\section{Considerações Finais}

A integração territorial brasileira, ao longo da história do país, foi posta como uma árdua luta de várias gerações para conectar esses espaços que se encontravam distantes das áreas centrais.

Os meios ainda eram simples e não possuíam força de interligação, excetuando as ferrovias que foram essenciais no continente europeu nesta função no período da I e II Revoluções Industriais, mas que no Brasil eram meramente utilizados para unir locais de produção a pontos de destino destas mercadorias, não suscitando em uma integração de fato.

A junção de Getúlio Vargas e Assis Chateaubriand fora fundamental para termos um Brasil integrado, com relação aos seus espaços, desmistificando a ideia de "ilhas" nacionais. A infra-estrutura para tal, elaborada pela política varguista de ampliação e construção de elementos concretos vinculada à divulgação destes feitos através dos organismos associados de Chateau, foram fundamentais para se construir as bases visando à integração nacional.

O Brasil vai se encontrar conectado de fato, após a II Guerra Mundial. No seu retorno à presidência em 1950 Getúlio tem um país bastante diferente daquele que assumiu vinte anos antes. Cidades cresciam em ritmo acelerado devido ao impulso gerado pela industrialização, aumentava o número de estradas de rodagem em detrimento das ferrovias, unindo pontos antes distantes e os Diários Associados encontravam-se no seu período áureo, como um conglomerado da informação com quase uma centena de jornais, emissoras de rádio e revistas, inserindo mais um instrumento de dominação e proliferação dos seus ideais e interesses: a televisão.

Nesse segundo momento, observa-se uma nova nação construída com a possibilidade, pela primeira vez, de se pensar um projeto único para todo o Brasil a partir da colaboração de vários grupos com poder de dominação sobre o território.

Além do poder governamental e da mídia, os militares também foram um grupo que tiveram profundo interesse na integração nacional com vista à proteção do território brasileiro de invasões estrangeiras, principalmente dos vizinhos sul-americanos. O exército brasileiro na primeira metade do século $\mathrm{XX}$ foi bastante inspirado pela geopolítica alemã e que foram 
transplantados para cá com a intenção de, ao invés de ampliação do território como pregavam os pensadores alemães Ratzel e Ritter, proteção e salvaguarda dos limites fronteiriços. A integração ajudaria a criar um estado coeso capaz de possibilitar maior segurança ao país. Esse pensamento teve como principal nome o general Golbery do Couto e Silva, que tinha profundo desagrado tanto a Getúlio Vargas quanto a Assis Chateaubriand.

Mesmo com propostas contrárias e interesses diversos, a busca da coalizão territorial do Brasil por essas figuras notáveis demonstrava a importância que esse tema possuía nas décadas de 1940 e 1950. Cada grupo com seu respectivo interesse colaboraram para construir a formação territorial que o país possui atualmente e a interligação entre seus espaços, executando um primeiro passo decisivo na integração nacional brasileira.

\section{Referências}

ANDRADE, Manuel Correia de. Geopolítica do Brasil. São Paulo: Ática, 4 ed., 1995.

ANDRADE, Manuel Correia de \& ANDRADE, Sandra Maria Correia de. A federação brasileira: uma análise geopolítica e geo-social. São Paulo: Contexto, 2 ed., 2003 [1999].

BARATA, Mario. Presença de Assis Chateaubriand na vida brasileira. Rio de Janeiro: Martins, 1971.

CARNEIRO, Glauco. Brasil, primeiro: história dos diários associados. Brasília: Fundação Assis Chateaubriand, 1999.

CASTRO, Ruy. O Anjo Pornográfico: A vida de Nelson Rodrigues. São Paulo: Companhia das Letras, 2 ed., 2004 [1992].

CHATEAUBRIAND, Assis. O pensamento de Assis Chateaubriand: artigos publicados em 1928. Brasília: FAC, v. 5, 1998.

CORRÊA, Roberto Lobato. Região e Organização Espacial. São Paulo: Editora Ática, $7^{\text {a }}$ edição, 2002.

COSTA, Wanderley Messias da. Geografia Política e Geopolítica: discursos sobre o território e o poder. São Paulo: Hucitec/EdUSP, 1992.

DIÁRIOS Associados. Sítio da rede de comunicação criada por Assis Chateaubriand com informações sobre os órgãos atuais pertencentes ao grupo, história e sobre a fundação de fomento à pesquisa. Disponível em: <http://www.diariosassociados.com.br>. Acesso em: 19 jun. 2009. 
DIAS, Leila Christina. Redes: Emergência e Organização. In: CASTRO, Iná Elias de; CORRÊA, Roberto Lobato; GOMES, Paulo César da Costa (Orgs.). Geografia: conceitos e temas. Rio de Janeiro: Bertrand Brasil. 2005 [1995], $7^{\text {a }}$ ed., pp. 141-162.

. Os sentidos da rede: Notas para discussão. In: DIAS, Leila Christina; SILVEIRA,

Rogério L. Lima da (Orgs.). Redes, sociedade e territórios. Santa Cruz do Sul: EDUNISC, 2005, pp. 11-28.

FAUSTO, Boris. Getúlio Vargas: o poder e o sorriso. São Paulo: Companhia das letras, 2006.

FERRAZ, Fernando G. Territorialidade, redes técnicas, urbanização/ metropolização e identidades socioculturais. Projeto de Regime de Tempo Contínuo (RTC). Salvador: UCSal, jul. 2002.

Brasil: O transe de uma terra em trânsito territorialidade, técnicas e rede urbana no Brasil. In: FERRAZ, Fernando G. (Org.). Coleção Textos de Graduação: Reflexões sobre espaço-tempo. Salvador: UCSal / Quarteto, 2004, pp. 11-34.

GEIGER, Pedro. As formas do espaço brasileiro. Rio de Janeiro: Jorge Zahar Editor, Coleção Descobrindo o Brasil, 2003.

MAGNAGO, Angélica Alves. A divisão regional brasileira - uma revisão bibliográfica. Revista Brasileira de Geografia. Rio de Janeiro, v. 57, n. 4, 1995, p. 65-92.

MENDONÇA, Marina Gusmão de. O demolidor de Presidentes: A trajetória política de Carlos Lacerda 1930-1968. São Paulo: Códex, 2002.

MORAIS, Fernando. Chatô: O rei do Brasil, a vida de Assis Chateaubriand. São Paulo: Companhia das Letras, 1994.

PRADO JÚNIOR, Caio. História Econômica do Brasil. São Paulo: Brasiliense, 48 reimpressão, 2008 (1945)

RAFFESTIN, Claude. Por uma geografia do poder. São Paulo: Ática, Tradução: Maria Cecília França, 1993.

SANTOS, Milton. Técnica, espaço tempo: Globalização e meio técnico-científico informacional. São Paulo: Hucitec, 3 ed., 1994.

SANTOS, Milton \& SILVEIRA, Maria Laura. O Brasil: território e sociedade no início do século XXI. Rio de Janeiro: Record, 9 ed., 2006 [2001].

SILVA, Golbery do Couto e. O espaço Brasileiro I (1952). In: SILVA, Golbery do Couto e. Geopolítica e poder. Rio de Janeiro: UniverCidade, 2003. p. 29-52.

Sístoles e Diástoles (1980). In: SILVA, Golbery do Couto e. Geopolítica e poder. Rio de Janeiro: UniverCidade, 2003. p. 478-500. 
SOUZA, Marcelo José Lopes de. O território: sobre espaço e poder, autonomia e desenvolvimento. In: CASTRO, Iná Elias de; CORREAA, Roberto Lobato; GOMES, Paulo César da Costa (Orgs.). Geografia: conceitos e temas. Rio de Janeiro: Bertrand Brasil. 2005

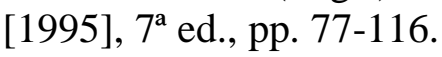

WAINBERG, Jacques A. Império de palavras. Porto Alegre: EDIPUCRS, 2 ed., 2003 [1997].

WAINER, Samuel. Minha razão de viver: memórias de um repórter. São Paulo: Planeta do Brasil, 2005. Organização e edição de textos por Augusto Nunes.

UEDA, Vanda. Dinâmica do território em redes: implantação e difusão do telefone no Rio Grande do Sul. In: DIAS, Leila Christina; SILVEIRA, Rogério L. Lima da (Orgs.). Redes, sociedades e territórios. Santa Cruz do Sul: EDUNISC, 2005, pp. 157-75. 